and, finally, the divided ends of the bowel should be secured to the margins of the abdominal wound, and an artificial anus established. This artificial anus can, at a future time, be closed by the now familiar resection operation, and the loop, so united, returned into the abdomen. The practice of uniting the divided ends of the bowel, immediately after the resection, is, for many very pressing reasons, to be condemned.

It may be well to point out that neither enterotomy nor colotomy can lay claim to be of value in the treatment of non-exceptional cases of intussusception. These operations certainly relieve the obstruction; but they leave in the abdomen an invaginated intestine, in which the process of inflammation and gangrene can still advance.

The operation of resection has now had an extended trial. Reichel, in a recent paper, collected one hundred and twenty-one cases in which the procedure was carried out. The technical details of the operation have been elaborated, and this method of treatment bids fair to play an important part in the future of abdominal surgery.

\section{THE MANAGEMENT OF THE THIRD STAGE OF} LABOUR.

Read in the Section of Obstetric Medicine at the Fifty-Secona Annua Meeting of the British Medical Association.

BY WM. J. SMYLY, M.D.,

Gynæcologist to the City of Dublin Hospital, etc.

THE third stage of labour is the period between the birth of the child and the exclusion of the after-birth ; including in the latter term the placenta, funis, and membranes. I have been asked to open, or rather to re-open, the discussion of this subject, which, though apparently simple, has always been an obstetric battlefield.

The subject is one of the greatest importance both as regards the mother and her child, and it cannot be doubted by any one who has seen much midwifery practice, or who has read the cases published in the medical periodicals, that, even at the present time, numbers of lives are lost through mismanagement of this stage of labour.

The subject divides itself into two parts ; first, as regards the mother ; and secondly, as regards the child. I shall confine myself to the former of these, namely, What is the best method of conducting the third stage of labour so as to insure the safety of the mother? And here I would state, as the great fundamental truth, the aphorism of Professor Credé, that, " the uterus itself should expel the afterbirth, and the sooner it does it, after the expulsion of the fœtus, the better. If it do not do so it must be made to, otherwise it may be too late, and the dangers of retained placenta come into force." If this be true, and I cannot imagine any grounds for thinking that it is not so, it altogether eliminates such practices as pulling upon the cord ; attempting to express the placenta from a relaxed uterus; "the imitation of the pains when absent," as recommended in one of our most popular text-books ; or the introduction of the hand into the uterus, unless in cases of absolute necessity. Of all these methods, perhaps the most disastrous is that of pulling on the cord, resulting, as it has done, in its avulsion, entire or partial, with retention of the placenta and membranes; irregular and inefficient contraction; and partial or complete inversion of the uterus, and violent hæmorrhage. All these dangers have been so frequently dwelt upon, that one might have hoped that by this time the practice would have been entirely abandoned; but this does not appear to be the case, and amongst a series of communications on the subject of hour-glass contraction of the uterus, which appeared this year in the British Medical Jourral, is one by a gentleman who not only admits having pulled upon the cord, but adds that "anyone else would have done the same." Neither does it seem to have occurred to him that the anomaly which he describes was the result of his own mismanagement. Such practice destroys the natural mechanism of placental delivery, and is almost invariably followed by considerable loss of blood.

If, then, the uterus is the proper agent, not only for the completion of the birth, but also for the extrusion of the after-birth, why not regard the third stage as a physiological process, and, just as in the other two, observe, unless in case of absolute neoessity, a purely expectant attitude? This inactive method has been adopted in some of the Continental hospitals, and has been advocated by Drs. Ahlfeld, Teuffel, and Kabierske, the last of whom has set forth the following propositions. 1. "The natural powers of normal labour are sufficient for the perfect separation of the after-birth, and the completion of the placental stage, and do so much better and more completely without artificial aid than with it. 2. The expectant treatment of the placental stage is free from danger."

The first of these propositions is true, and is borne out by statistics. The method adopted in the Strasbourg clinic was, in normal cases, expectant: the state of the uterine contraction being from time to time observed, as well as the amount of discharge; and the bladder and rectum were carefully attended to. Thus hours were often allowed to pass, without any attempt to remove the placenta, even though lying in the vagina. Out of 100 cases treated thus, the placenta was expelled in 69 within three hours. This is more rapid than the observations of others would have led us to expect, and was probably, in some measure, due to the action of the bladder and rectum; for it was usually during an effort to relieve either of these viscera that the placenta was expelled. The old wives' plan of giving the woman a pinch of snuff would be equally efficacious and more agreeable.

By this method it is alleged-and this is the strongest point in its favour-that the membranes, and especially the decidua, are much more completey separated than by a more active one. Instead of being expelled as a thin, and in many places imperfect, membrane, the decidua was found to be by far the thickest portion of the coverings of the ovum. Thus the expectant plan appears to be followed by a better separation of the decidua; but, on the other hand, it is liable to be attended by violent hæmorrhages, which not only immediately imperil the patient's life, but subsequently tend to relaxation of the uterus, permitting the formation of clots within its cavity, which by decomposition might occasion putrid infection. Even Kabierske himself admits that the average amount of blood lost in his cases was greater than that recorded by others; and, though he makes light of this circumstance, there is good reason to believe that it was often sufficient to occasion alarm. It also permits irregular contrac tion of the uterus, and incarceration of the placenta, necessitating more frequent introduction of the hand, and thus increasing the liability to septic inoculation. Besides, the long delay is not only irksome to all concerned, but is calculated to excite and alarm the patient and her friends. The second proposition, "that the expectant treatment is free from danger," must therefore be rejected as not borne out by facts.

The relative results of the expectant and a more active methods of treating the placental stage are clearly shown by the following statistics by Dr. Weir of Copenhagen.

$$
\text { Cases treated. }
$$

Post partum hæmorrhage

Manual removal of placent

Retention of membranes

$\begin{array}{ll}\text { Expectantly. } & \text { Expression. } \\ 5.78 \text { per cent. } & 2.3 \text { per cent. } \\ 1.33 \quad " & 0.64 \quad " \\ 1.78 \quad " & 2.3 \\ 0.77 \quad " & 0.32 "\end{array}$

From these statistics, it appears that the only advantage of the expectant method is that retention of the membranes is less frequent but, in spite of this, and contrary to what might have been expected, secondary hæmorrhage is more so.

The results of the expectant method should teach us to keep a constant control over the uterus, by holding it with the hand, and never allowing it to relax. This is the method which has been practised in the Dublin Lying-in Hospital for upwards of a century, and is similar to that introduced into Germany by Professor Credé. A good deal of controversy has arisen as to whether these two methods, namely, the Dublin method and Credés, are the same or different. I shall, therefore, describe them separately, and afterwards compare them with each other.

The Dublin method has been followed in the Rotunda Hospital certainly since the mastership of Dr. Clarke in 1789. It was described by Dr. Dease, of Dublin, in 1783, and by Drs. Hardy and McClintock, in 1848. I shall quote their description (Practical Observations on Midwifery, p. 221)

"Having placed the hand on the fundus uteri, friction and slight pressure are to be made, and, if the amount of contraction thereby induced be not sufficient to repress the hæmorrhage, it will be necessary to expel the placenta from the cavity of the uterus. In doing this, the organ must be grasped firmly, and pressure exerted upon it in the axis of the brim of the pelvis. If the uterus have fallen to the left side, as not uncommonly happens, it must be raised into its natural position, before commencing to exert compression upon it. It will also tend much to the success of the manipulation, if it be performed during the presence of uterine action. Indeed, we have sometimes been surprised at the ease with which the placenta was pressed off during a contraction of the uterus, while previously it had withstood our best directed efforts. These measures we have seldom found to fail in getting away the placenta, unless it be morbidly adherent."

In 1853 Professor Credé first published an account of his method. 
Quite unacquainted with the Dublin practice, he was led to the discovery in the following way. Being frequently called to cases of retained placenta attended with hæmorrhage, he found that examining the uterus externally was often sufficient to excite so violent a contraction as to expel the placenta even outside the vulva.

So gratified was he. by this unexpectedly favourable result, that he adopted a similar treatment in every case, with marked success. $\mathrm{He}$ recommends that, as soon as possible after the birth of the foetus, the hand should be placed over the region of the uterus, making, at first, gentle stroking movements, until it is felt as it commences to contract beneath the fingers; then, as the contraction reaches its acme, the organ is grasped in one or both hands, the fingers being spread out over it; thus its walls are squeezed together, and pressure is made towards the coccyx.

The chief puint is, to seizd the exact moment when the contraction is at its height. By this method, in a favourable case, the afterbirth can be expelled by a practised hand, with the first or second afterpain. As a rule, however, it follows with the third or fourth, that is, in about five minutes. If it do not come, he waits for more pains, and acts in a similar manner with each ; it seldom requires more than fifteen minutes. He specially cautions against impatience or violence in manipulation.

Each of these methods has some distinct advantages. By following its contraction, the intestines are prevented from falling down in front of the uterus, and thus pressure can be made more directly upon it. By never allowing it to relax, irregular contraction and hamorrhage are avoided, so far as is possible. Professor Spiegelberg lays great stress on the importance of this practice. "It is not," he says, "identical with Credé's method. Whilst in the latter the hand is placed upon the uterus after the birth of the child, and by powerful ifritation excites it to contraction; I lay the chief stress, after the example of the Dublin Lying-in Hospital, upon the immediate general contraction of the uterus, whilst through this the separation of the placenta is brought about; and this, not the expression, is the chief point. Thus from the birth of the head, by following the uterus, and by mechanically exciting it, I make the contraction, which necessarily accompanies the expulsion of the fotus, both energetic and continuous. Thus I often obtain rapid separation of the placenta, and prevent irregular contraction of the uterus. In Credés method, irregular contraction may set in, unobserved, betwcen the birth of the child and the commencement of the process; whilst by the above method this is impossible." The importance of this point is also illustrated by two cases published by Dr. Garrigues, in which violent, and in one case fatal hæmorrhage occurred, before Crodé's method could be practised (Amer. Jour. of Obstet., May, 1884).

In Credé's method, friction and pressure are more actively and systematically carried out than in the Dublin method, and so the ex. pulsion of the placenta is hurried; but the liability to retention of the membranes is increased. The importance of this latter complication is at present, however, uncertain. The expulsion of the placenta from the vagina by pressure alone, without introducing the fingers into the ragina, is a decided improvement, and is the natural outcome of antiseptic teaching. That it was not appreciated by Irish obstetricians, more than one hundred years ago, is not to be wondered at, yet Dr. Carrigues has seized upon this one point to disparage altogether what he contemptuously designates the "so-called Dublin method." It is much more surprising that he should himself, according to his own confession, have practised until eight years ago " the old way of pulling on the cord."

My own belief is that a mixed method, combining the advantages of the Dublin with those of Crede's method, is the best possible. The following are the most important points to attend to. Follow the contracting uterus, as it expels the child, and by pressure and friction make this contraction energetic and permanent. Never let it go, unless compelled to do so; and then always provide a substitute, the anrse, a friend, or even the patient herself. It is wrong to resign such an important function, simply to tie and divide the navel string. During a contraction, press the uterine walls together, and the entire organ towards the coccyx. When sudden flattening of the uterus shows that the placenta has been expelled from it, then by strong pressure downwards drive it out of the vagina. The placenta should not be shot out upon the bed or into a vessel held against the buttocks, since the membranes are thereby liable to be torn across, but it should be received in the hand at the vulva, and rotated so as to twist the membranes into a firm cord which is easily withdrawn, without, as a rule, leaving any portions behind. Should this accident, however, occur, I think it is less dangerous to leave them than to introduce the hand for their removal ; but should they prove a cause of hinrnorrhage thoy must be taken away.
Finally, I quite agree with Dohrn, Runge, and others, that beneficial as is the active method when properly employed, just so injurious is it when unskilfully carried out. The hasty and violent expression of the placenta from an imperfectly contracted or relaxed uterus is a frequent cause of retention of the membranes and portions of placenta, as well as of violent hæmorrhage and fever.

Mr. OLPHERTs (Downpatrick), having been educated in the Dublin School of Medicine, had imbibed the theories which had been enun. ciated by Dr. Smyly ; and the longer he continued to practise, the more was he satisfied with the practical benefits of the Dublin plan of treatment of the third stage of labour. As a medical officer of a large country district, he must also take into consideration the utter im. practicability of the expectant treatment where much of the practice was at a considerable distance from the residences of medical men. They could not wait for long periods, nor could they with safety leave their patients in charge of midwives. There was also the risk of injury to the mother, liable to ensue from prolonged anxiety.

Dr. ABRAHAM KIDD (Ballymena) considered that one hour would be too long to wait for the expulsion of the placenta. After thirty minutes, he would resort to measures for its removal, believing that, in case of irregular contraction or morbid adhesion, a longer delay would increase the difficulty of introducing the hand.

Dr. Mullax (Ballymena) agreed with all that Dr. Smyly had said, but one point was not clearly brought out: the need of giving the uterus rest after it had expelled the child. The uterus was a muscle, and, like all muscles, became more or less exhausted by effort. After a few minutes' rest, the uterus would expel the placenta, when otherwise it could not do so. The rules recommended by Dr. Smyly deserved attention.

Dr. WALTER (Manchester) said that there was one very important item in the treatment of the third stage of labour which had not been alluded to by the previous speakers, namely, the advantage to be obtained by placing the patient on her back as soon as the second stage of labour was completed. In this position, any clots that had formed could more easily escape, whilst the attendant had more perfect control over the uterus. If slight frictions and gentle pressure over the fundus were insufficient to excite uterine contractions, the organ would be more firmly grasped, one hand being placed against the anterior wall, and the other against the posterior. By this means, both walls of the uterus would be pressed together; if downward pressure of the uterus were needed, it could be resorted to at the same time, and much more efficiently than if the patient had continued to lie on her side.

Dr. MURPhy (Sunderland) said that the management of the third stage of labour was of very much greater importance than was generally imagined. He agreed with what Dr. Playfair stated in his valuable book, that the man who was continuously meeting with cases of post partum hæmorrhage did not know his work. It was a lamentable fact that; as Dr. Smyly had stated, some practitioners still attempted to remove the placenta by traction on the cord, though Dr. Matthews Duncan pointed out long ago that, instead of the placenta doubling up and emerging from the os, the centre protruding first, the placenta folded upon. itself and emerged edgeways. In his own practice, he always gave a full dose of ergot a quarter of an hour before he expected the birth of the foetus. He then held the uterus with his hand, following it well down, and kept up gentle but firm pressure till the placenta came away. To do this he got the nurse to tie the cord, and to cut it, and if he found the uterus not contracting, he applied a little friction; if he found the uterus hardening, he got his hand well on the top of and behind the uterus, and firmly squeezed out the placenta. The result was that he seldom saw more than a few drops of blood.

Mr. T. M. WATT (Hovingham) stated that his experience of the expectant treatment had been confined to cases where he arrived after completion of the second stage, and that his experience of post partum hæmorrhage was limited to these same cases. He thought it the imperative duty of the medical attendant, following down the uterus during the expulsion of the fotus, to retain it there, keeping the uterus under his personal control until expulsion of the secundines and permanent uterine contraction had taken place; as, in many instances, where he had entrusted to women, however experienced, the duty of keeping up manual pressure after the birth of the child, he had found, on resuming his post, the uterus enlarged by less or more internal hæmorrhage.

Dr. Thomas ElliotT (Tunbridge Wells), was much struck by the entire omission from Dr. Smyly's paper of one most important point ; namely, to be perfectly sure that the placenta was entirely separated before making any attempts at expulsion, whether by expression, traction on the cord, or any other method. The evidence of separation 
of the placenta was the pulseless and flabby state of the cord. When this was obtained, then each case could be treated on its own merits ; if there were hæmorrhage, more or less active interferenco. was required. If there were no hæmorrhage there really was no need: for active interference, and simple means, such as gentle friction or expression, would often cause the placenta to comie away.

MIr. WADDBLL (Newry), related a case which had occurred in his practice, in 1866. He was called to a woman in the sixth month of pregnancy, and found her in labour. She was delivered of a dead fœtus, the placenta of which, after it had become detached, he removed. At the same time he felt the movements of another child. This was retained, and the woman was delivered of a healthy boy at full term, three months afterwards. He believed that if he had been in too great a hurry to remove the first placenta and had employed the usual means for doing so, the second child would have been lost.

The Presidennt (Dr. Godson), considered that very different ideas were entertained as to the meaning of the terms "Expression of the placenta," and " Expectant method." $\mathrm{He}$ could not over-estimate the importance of placing the hand on the uteras immediately after the birth of the child, and keeping it there, if possible, until the separation of the placenta. Gentle kneading of the uterus to excite contractions was one thing, and forcing out the placenta, which invariably turned the membranes inside out, with a great tendency to leave some portions behind, was another. Such a plan was objectionable, and should only be had recourse to in cases of hrmorrhage or continued inertia, which the administration of ergot of rye and beef-tea, and, perhaps, a small quantity of stimulant, would not overcome. Compression of the uterus, after the removal of the placenta, to expel clots, was of great use; but, if the uterus could be coaxed to expel the placenta itself-a fair amount of patience being exercised-it was far better than forcibly expressing it.

\section{THE TREATMENT OF LUPUS.}

\section{Road in the Section of Medicine at the Fifty-Sccond Annual Meeting} of the British Medical Association.

BY J. HERBERT STOWERS, MI.D.,

Physician to Department for Skin Diseases, North-West London IIospital.

IN accordance with the excellent rule of our Association, that communications read at the sectional meetings should be both as concise and brief as possible, I do not desire to discuss at this time the whole subject of the treatment of lupus. So numerous, and indeed various, have been the suggestions in the past, that, until comparatively recently, the experience of dermatologists has not been sufficiently comllete to decide whether. gieater advantages are to be obtained from the use of caustics, or other methods.

My own opportunity of dealing with the disease has been consider. able enough to allow me to form some judgment as to the relative inelits of most of them; and it is on account of the fact that I have observed more satisfactory results by far from the combined use of the scoop and nitrate of silver, that I have resolved to ask your special consideration of the method of treating lupus by erasion or scraping.

I purposely refrain saying anything here concerning internal remedies, so necessary as they are to correct the general failure in health, or predisposition to the local development, neither can I stay to review the local treatments in their entirety.

The process of erasion advocated by Volkmann is carried out by means of a small hollow and elongated spoon, or scoop, with a moderately sharp edge, set in an ivory or bone handle. The special advantage is, that when the scoop is applied with considerable force, all the diseased tissue, or cell-growth, which is exceedingly vascular and friable, immediately breaks down, and is removed, while the healthy surrounding structures of the skin are too dense and fibrous to be included in the operation.

Those who have had experience of this method, will concur as to the remarkable way the soft, spongy, boggy tissue yields to the scoop, and how much more certainly can the extent and depth of the disease in this manner be estimatel. All the cases I have treated thus have been of long duration, and the new growth in each has existed over an extensive area.

The operation should not be undertaken except with the aid of an anæsthetic, for much of its after success depends upon the complete removal of every tubercle, and, consequently, occupies a considerable period of time. With so vascular a structure also, much hæmorrhage results which should be entirely arrested before thie solid nitrate of silver is used. I repeat-for it cannot be too carefully noted-that thorough eradication of the abnormal growth n!ust be secured before the scoop is laid aside. In several instances I have operated upos large masses of disease situated over the great vessels of the neck, and, despite the force required, I can truly assert that, with even moderatp care, no danger occurs of wounding them.

When the process of scraping is completed, and the hremorrhage arrested (local depletion being, doubtless, an aid to results), the serous discharge escaping from the wounds should be carefully soaked up with clean blotting-paper. Attention to this latter point will obviate the risk of the dissolved caustic running over the surrounding healthy integument, and so adding needlessly to the suffering of the patient.

It is necessary that the nitrate should be pushed deeply into the holes and interstices left by the instrument; in fact, it should be made to burrow into the tissues quite as extensively and deeply.

Considerable inflammation of course follows, which assists ultimate absorption ; but the intensity of the pain does not last nearly so long as that attending the use of other caustics.

The parts should be dressed with lint well saturated with carbolised oil, the next day more oil being allowed to run under the dressing. The second day after the operation, when suppuration has commenced, fresh carbolised oil-dressings should be applied, and so on daily. So severe is the smarting if water be used, that it is preferable, until the discharge is considerable, to cleanse the part by gently rubbing with lint dipped in olive-oil, to which a drop or two of carbolic acid may be added. Later, when the sloughs are separating, a weak carbolic acid lotion is advisable for the same purpose, and may with advantage be used with a syringe.

In the cases under my care, which have been, so far, attended with permanently good results, it was necessary to repeat the operation at intervals varying from six to eighteen months; indeed, in some, several repetitions have been compulsory. But I contend, and that very strongly, that, if every new tubercle be immediately attacked, the instances will be few and far between, if any, in which, with the addition of appropriate internal and constitutional treatment, the tendency to new development will not be outmatched.

The destructive results of this rebellious affection are too well known to require a word more in this direction ; suffice it to say that in five cases, at least, I have secured noses marked now with a relatively limited scarring, which would otherwise (if left without local treatment) have broken down by extending disease and secondary ulceration, to the production of irremediable and hideous deformities.

The natural tendency to recur must never be accepted as sufficient reason for not contending again and again with the disease until that age or condition of health be reached which will secure lasting and permanent immunity.

I would recommend, not less strongly, that any neighbouring tissue, while suspicious in character, though not readily breaking down under the scoop, should be freely submitted to multiple punctiform or linear scarification, combined with a liberal use of the solid nitrate of silver.

Three cases alone, taken from my note-book, will suffice to illustrate practically the value of the above treatment, and with these I conclude.

CASE 1.-Emily D., aged 20 in July 1883: Extensive lupus of nose. Residing at Chislehurst. Duration eight years. Four operations under ether: one in 1881 ; two in 1882; one in 1883 (February). No return up to present date. Cicatrices well formed, and healthy.

CASE II.-Anne K., aged 27 in 1877. Residing in Bedfordshire. Extensive lupus of cheek. Duration twenty years. Two operations under ether: one in January 1881 ; one in 1882 . No return up to pressent date. Parts look quite healthy.

CASE III.-Elizabeth C., aged 19 in 1880. Lupus of nose. Duration nine years. Three operations during 1880 and 1881. Perfect scar-tissue now remaining. No evidence of disease returning.

Bicarbonate of SodA in Tonsilitiris.-In the early stages of tonsillitis, before the pain of swallowing is excessive, Dr. G. Partagas alleges that bicarbonate of sode will arrest the inflammation. He makes the application in the following manner. The index finger being moistened, is charged with as thick a layer of the powder as will adhere to it; and is then introduced into the mouth and rubbed thoroughly over the inflamed tonsil. Five or six applications are thus made at intervals of five minutes. At the end of this time, Dr. Partagas has found that the patient will find the act of swallowing 1learly painless. When thus employed in the early stages, bicarbonate of soda will cut short the disease, and later will promote resolution. In hypertrophy of the tonsils, two or three applications of the powder each day will reduce the size of the glands very considerably in one or two months. 